\title{
Review
}

\section{Progress in Genetic Manipulation of the Brassicaceae}

\author{
Nasar Uddin Ahmed · Jong-In Park · Hye-Ran Kim · III-Sup Nou
}

Received: 27 February 2012 / Accepted: 10 March 2012

(c) Korean Society for Plant Biotechnology

\begin{abstract}
With the increasing advances in Brassicaceae genetics and genomics, considerable progress has been made in the transformation of Brassicaceae. Transformation technologies are now being exploited routinely to determine the gene function and contribute to the development of novel enhanced crops. Agrobacterium-mediated transformation remains the most widely used approach for the introduction of transgenes into Brassicaceae. In Brassica, the transformation relies mainly on in vitro transformation methods. Nevertheless, despite the significant progress made towards enhancing the transformation efficiencies, some genotypes remain recalcitrant to transformation. Advances in our understanding of the genetics behind various transformations have enabled researchers to identify more readily transformable genotypes for use in routine high-throughput systems. These developments have opened up exciting new avenues to exploit model Brassica genotypes as resources for understanding the gene function in complex genomes. Although many other Brassicaceae have served as model species for improving plant transformation systems, this paper summarizes on the recent technologies employed in the transformation of both Arabidopsis and Brassica. The use of transformation technologies for the introduction of desirable traits and a comparative analysis of these as well as their future prospects are also important parts of the current research that is reviewed.
\end{abstract}

Keywords Brassica, Brassicaceae, Improvement, Transformation

N. U. Ahmed · J.-I. Park $\cdot$ I.-S. Nou ( $ه)$

Department of Horticulture, Sunchon National University, Suncheon, 540-742, South Korea

e-mail: nis@sunchon.ac.kr

H.-R. Kim

KRIBB-Plant Systems Engineering Center, Daejeon, 305-806, South Korea

\section{Introduction}

The Brassicaceae family includes many economically important edible and industrial oilseed, vegetable, condiment, and fodder crop species. Cultivated Brassica species are a group of crops most closely related to Arabidopsis thaliana, and are members of this family. Oilseed Brassicas are found within Brassica juncea, Brassica carinata, Brassica rapa and Brassica napus, and are commonly called oilseed rape. Vegetable Brassica are an important and highly diversified group of crops grown worldwide, and belong mainly to the species B. oleracea, as well as B. rapa and B. napus. This group includes plants such as broccoli, Brussels sprouts, cabbage, cauliflower, collards, kale, kohlrabi, rutabaga, and turnip. Brassica vegetables contain little fat, and are sources of vitamins, minerals, and fiber. Several species, e.g., Camelina sativa, Crambe abyssinica, Eruca vesicaria, have potential as new edible oil/protein crops, biodiesel fuel crops, or platforms for bioproducts or molecular farming (Warwick et al. 2006). The family is also known for its more than 120 weedy species, several of which are important cosmopolitan agricultural weeds (e.g., wild mustard (Sinapis arvensis)), stinkweed (Thlaspi arvense) while others form crop-weed complexes (e.g., Raphanus sativus-Raphanus raphanistrum). Several of these related weeds are able to exchange genes, including transgenes, with crops under natural field conditions (reviewed in Warwick et al. 2003, 2008), potentially increasing weediness. Although most research in Brassica crops has been performed on oilseed and vegetable biotypes, rapid-cycling Brassica biotypes of various species have gained attention.

In recent years, considerable research has been conducted in the transformation and molecular breeding of Brassicas. As a research tool, transformation initially focused on the overexpression of the gene(s) of interest using the genes isolated from models and then later homologous crop genes, or the use of reporter genes to assess specific 
endogenous promoters. Most of the common reverse genetics approaches (the ability to knock out or silence genes) are also based on transformation techniques, such as TDNA insertion (Alonso et al. 2003), RNAi (Horiguchi 2004), artificial miRNA (Schwab et al. 2006), antisense (Ecker and Davies 1986), or the newly developed "target mimicry" techniques (for knocking down miRNA function) (Franco-Zorrilla et al. 2007). All of these techniques have been shown to work in A. thaliana and are also now beginning to be applied in Brassica species. Areas of particular interest include biotic and abiotic stress tolerance (Cao et al. 2008; Purty et al. 2008), oil synthesis (Mietkiewska et al. 2008) and plant architecture (Østergaard et al. 2006). With increasing knowledge of the function of genes, as well as the development of techniques for plant transformation, the potential for further improvement through Genetic Modification (GM) of these species is also considerable. To date, GM B. napus is the only Brassica species to gain commercial regulatory approval. GM herbicidetolerant B. napus (canola) was the fourth most planted GM crop in 2007 (James 2007). The other major, socalled first-generation trait introduced into Brassica is the Bacillus thuringiensis toxin $(\mathrm{Bt})$ to prevent insect attack. Experimental Bt-producing B. napus lines (Halfhill et al. 2002) and B. juncea lines (Cao et al. 2008) have been developed, and in $B$. oleracea vegetable crops including broccoli (Cao et al. 1999), cabbage (Jin et al. 2000) and chinese cabbage (Cho et al. 2001) have had the Bt crylAc gene incorporated to control diamondback moth. On the other hand, the public perception of GM technology still hinders its global advancement, particularly in Europe. In the developed world, so-called next generation traits, such as modified oils containing increased Omega-3 fatty acids or broccoli with increased levels of antioxidants, as well as other such consumer-targeted traits that are likely to gain public acceptance.

This review presents relevant research with a view towards improving Brassicaceae crop plants with potential and desirable traits. This includes transgenesis and the advances made to Brassicaceae transformation methods, particularly the main Brassica species, as well as a discussion on how this technology can be exploited further to improve of Brassicaceae crops.

\section{Genetic transformation}

The relative ease of transformation and access to complete genomic sequences in Arabidopsis have led to an range of forward and reverse genetic approaches that provide great insight into the gene function. On the other hand, conservation of the gene function between Arabidopsis and Brassica can still be confirmed using transgenic approaches, such as complementation of an Arabidopsis mutant phenotype with a Brassica orthologue or mimicking overexpression phenotypes in both Arabidopsis and Brassica. Transformation systems have been developed in almost all economically important species of Brassica, such as $B$. juncea (Barfield and Pua 1991), B. napus (Moloney et al. 1989), B. rapa (Radke et al. 1992), B. oleracea (de Block et al. 1989), B. nigra (Gupta et al. 1993), and B. carinata (Narasimhulu et al. 1992). Poulsen (1996) reviewed a range of methods used for Brassica transformation and the factors affecting transformation efficiencies. Agrobacterium -mediated transformation (either A. tumefaciens or $A$. rhizogenes) still remains the favored delivery approach for the introduction of transgenes into most dicotyledonous plant species and is rapidly becoming a common practice for an expanding range of monocots (Bartlett et al. 2008).

\section{Agrobacterium-mediated transformation}

Interest in transforming Arabidopsis followed the adoption of $A$. thaliana as a model plant species in the $1980 \mathrm{~s}$ (reviewed by Somerville and Koorneef 2002), with a tissue culture-based $A$. tumefaciens-mediated transformation first reported in 1986 by Lloyd et al. (1986) and An et al. (1986). Further improvements in these methods were achieved using an in vitro root transformation method, which was recently adapted for Arabidopsis lyrata (FobisLoisy et al. 2007). Many publications reported improvements to tissue culture conditions and the use of reporter genes to determine the transformation efficiencies but the major limiting factor in many recalcitrant genotypes was still the poor tissue culture response and insensitivity to Agrobacterium. Progress was later made to identify and develop protocols that worked for a wider range of genotypes and Brassica species (Sparrow et al. 2006a; Bhalla and Singh 2008), as well as to identify suitable genotypes for use in routine transformation studies to test the gene function (Cardoza and Stewart 2006; Gasic and Korban 2006; Sparrow et al. 2006b). The simplest approaches using hypocotyls and cotyledons for Brassicaceae crop plants are described by different authors in different times with maximum transformation efficiency are mentioned in Table 1 . In cotyledon method, generally cotyledonary petioles dipped into a suspension of $A$. tumefaciens and co-cultivated for $72 \mathrm{~h}$ on selection-free media before transferring to a basic MS basal medium supplemented with between 2 and $4 \mathrm{mg} / \mathrm{l}$ 6-benzyl-aminopurine (BAP). The explants were then 
Table 1 Agrobacterium-mediated maximum transformation efficiency of different Brassicaceae species using hypocotyls and cotyledons explants

\begin{tabular}{lccl}
\hline \multirow{2}{*}{ Name of Species } & \multicolumn{2}{c}{ Transformation Efficiency (\%) } & \\
\cline { 2 - 3 } & Hypocotyls & Cotyledons & \\
\hline B. oleracea & 30 & 9.5 & References \\
B. napus & 30 & 68.1 & De Block et al. (1989), Bhalla and Singh (2008) \\
B. rapa & 1 & 9 & Wahlroos et al. (2003), Takasaki et al. (2004) \\
B. juncea & 16 & 16.2 & Gasic and Korban (2006), Bhuiyan et al. (2011) \\
B. nigra & 33 & - & Gupta et al. (1993) \\
B. carinata & 14 & 50 & Babic et al. (1998) \\
\hline
\end{tabular}

sub-cultured to fresh media after 2-3 weeks. Emerging shoots are isolated and rooted on a hormone-free medium (sometimes the addition of an auxin is needed). Hypocotyl methods use either pre-cultured hypocotyl segments (following a short callus induction period) or newly isolated hypocotyl segments immersed in a suspension of A. tumefaciens for 30-60 min. The explants were then washed and transferred to the co-cultivation medium for $48 \mathrm{~h}$ before transferring them to the selection medium. Both methods employ different media for callus induction, shoot induction, shoot elongation and rooting stages. Hypocotyl and cotyledonary petioles are used for Agrobacterium-mediated transformation in B. oleracea (Fig. 1, 2). Of the cultivated Brassica species, $B$. rapa remains the most recalcitrant to transform.
On the other hand, a limited number of successes have been reported: hypocotyl sections (Radke et al. 1992), cotyledonary petioles (Zhang et al. 2000), cotyledonary leaf sections (Yang et al. 2004), internodes from glasshouse -grown B. rapa (Kuvshinov et al. 1999), A. tumefaciens infiltration of whole plants (Qing et al. 2000) and microinjection of $A$. tumefaciens directly into flower buds (Yan et al. 2004). With the sequencing of the $B$. rapa genome currently underway (www.brassica.info.org) it is likely that efforts and interest in a $B$. rapa transformation will increase over the next few years. This will provide excellent resources to optimize the information arising from the Multinational B. rapa Genome Sequencing Project for Brassica functional genomics as it becomes available.
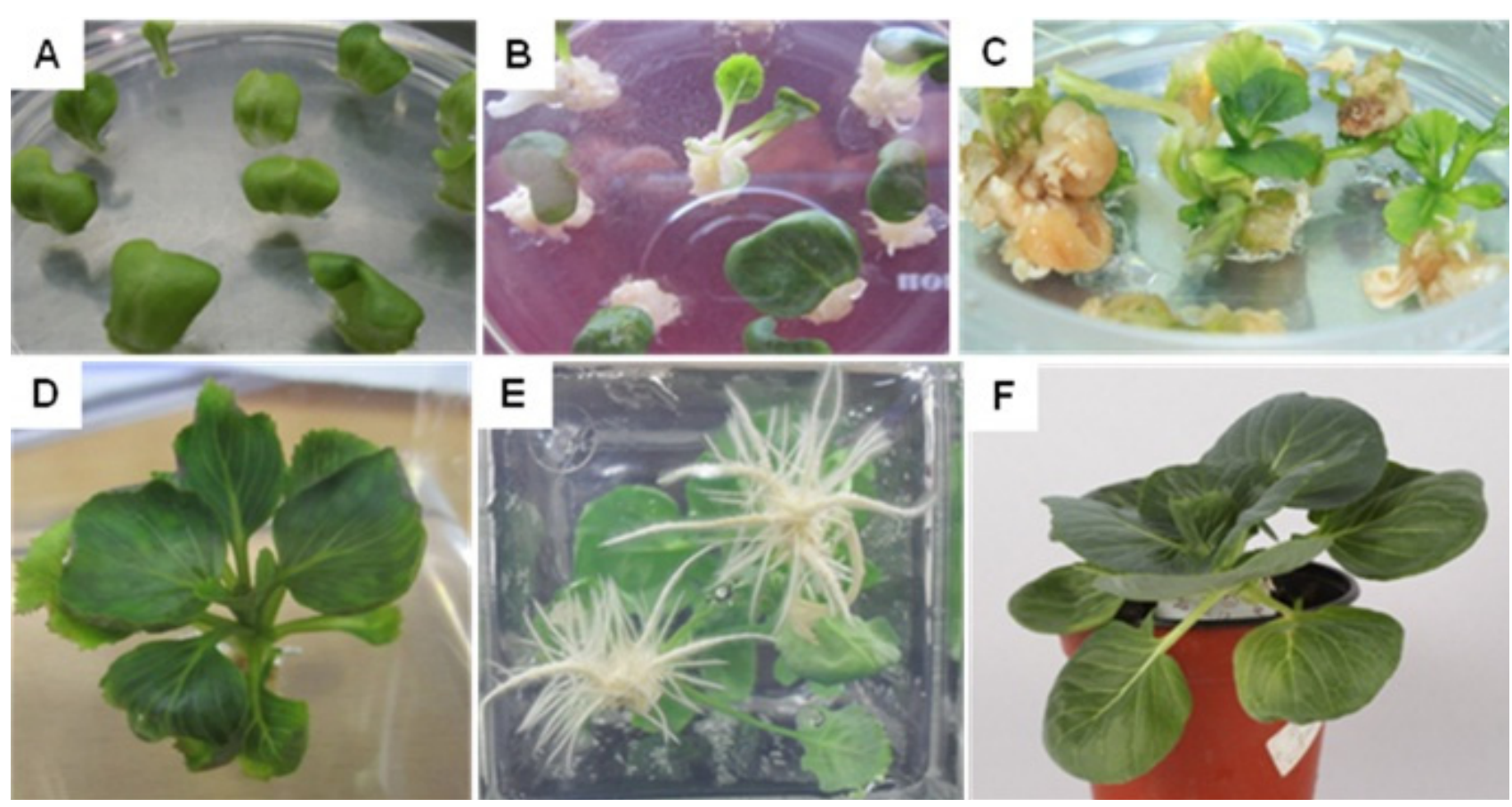

Fig. 1 Agrobacterium-mediated transformation using cotyledon explants in cabbage. A) Callus formation, B) Shoots differentiation, C) Shoot outgrowth, D) Transgenic plant selection in high antibiotic containing medium, E) Transgenic plants in rooting medium and F) Transgenic plant in soil 
A. rhizogenes is a soil bacterium responsible for the development of hairy root disease of dicotyledonous plants and has been used to transform more than 79 plant species in its modified form (reviewed in Christey 2001). This bacterium has been used successfully to transform Brassica, where the focus has been on B. oleracea and B. napus (Puddephat et al. 2001). Overall, the transformation rates were low, but in some cases, transgenic Brassica plants were obtained more efficiently via an $A$. rhizogenesmediated transformation than A. tumefaciens (Christey et al. 1997). The main disadvantage of using $A$. rhizogenes, however, was that $r o l$ genes were often transferred and expressed in plants regenerated from hairy roots, often exhibiting the associated altered phenotype, such as wrinkled leaves, shortened internodes, reduced fertility, and plagiotropic roots. On the other hand, these traits often segregated in the next generation, facilitating the recovery of normal transgenic plants (Puddephat et al. 2001). In Arabidopsis, A. rhizogenes root transformation of wild-type shoots (composite plants) is now being used for the "in root" gene testing of transgenes and plantmicrobe interaction studies (Veena and Taylor 2007). Owing to the small size of Arabidopsis, the procedure is carried out in vitro but non-tissue culture conditions can be used for larger plants. Collier et al. (2005) reported composite plant production in Brassica, in which the transgene expression of reporter genes in composite plant roots has been demonstrated.

Bacterial strains and plasmids

A number of different $A$. tumefaciens strains have been used successfully to transform Brassicaceae. GV3101 is used most frequently for Arabidopsis (Koncz and Schell 1986), whereas other disarmed strains of the C58 background can often be substituted with similar results. LBA4404 (Hoekema et al. 1983), an octopine strain, is also commonly used but generally works less well than GV3101. This lower efficiency is sometimes desirable for obtaining a greater proportion of transgenics with a low copy number (Bent 2006). LBA4404 is also used routinely in Brassica, as are the nopaline strains C58 (Sciaky et al. 1978) and derivatives AGL1 (Lazo et al. 1991) and EHA101 and EHA105 (Hood et al. 1986), which have all been used successfully and routinely. The use of GV3101, which is the preferred strain for an Arabidopsis transformation, has also been reported for Brassica (Mehra et al. 2000), even though its use in crops is far from routine. It is likely that over the next few years, the ability to use the plasmids and Agrobacterium strains used routinely for an Arabidopsis transformation will be highly desirable as researchers move their findings from model species to crops, such as Brassica. The type of plasmid used is believed to be less critical than bacterial strains, even
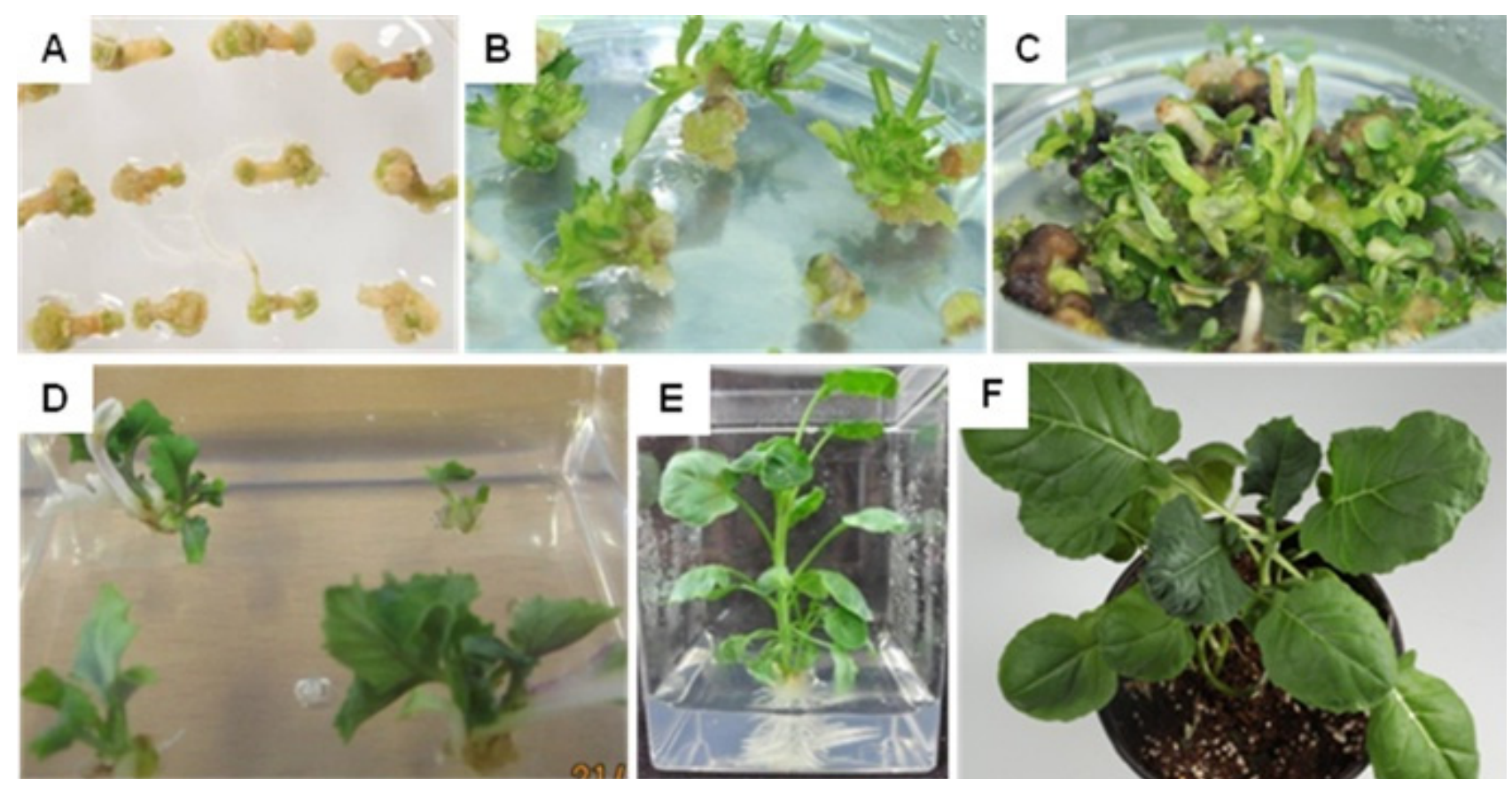

Fig. 2 Agrobacterium-mediated transformation using hypocotyl explants in broccoli. A) Callus formation, B) Shoots differentiation, C) Shoot outgrowth, D) Transgenic plants selection in high antibiotic containing medium, E) Transgenic plant in rooting medium and F) Transgenic plant in soil 
though the choice of promoters and selectable markers is important. The plasmids commonly used for Brassica are as follows: modified pBIN19 (Bevan 1984); SLJ vectors (Jones et al. 1992), SLJ1714 and SLJ1711; the pCAMBIA vectors, particularly pCAM2200 (www.cambia.org); and pGreen (Hellens et al. 2000, www.pgreen.ac.uk). The above examples are based on the $35 \mathrm{~S}$ promoter driving nptII, the favored selectable marker gene for Brassica, but other selectable markers are available.

Direct uptake transformation methods

Direct gene transfer of mesophyll protoplasts using PEGmediated transfer was demonstrated in Arabidopsis by Damm et al. (1989) as well as in Brassica by Mukhopadhyay et al. (1991) (using hypocotyl protoplasts) and Eimert and Siegemund (1992) (for mesophyll protoplasts) using either electroporation or PEG-mediated transfer for cauliflower protoplasts. Radchuk et al. (2002) examined a range of factors effecting a PEG-mediated transformation in Brassica using both kanamycin and hygromycin selection, and Nugent et al. (2006) reported a successful transformation in cauliflower mesophyll protoplasts using a gus reporter gene and hygromycin selection. Regeneration from protoplasts remains the main limitation of this approach. Another direct approach is biolistics or microparticle bombardment, where DNA-coated beads are fired into plant cells at high speed. This approach has been used successfully in B. napus and the target tissue was pollen (Fukuoka et al. 1998). These approaches again offer an alternative transformation method for the genotypes not susceptible to an Agrobacterium infection and are a useful approach for transient expression studies (Puddephat et al. 1999).

\section{Chloroplast transformation}

Plastid transformation offers a number of potential advantages over nuclear transformation (Maliga 2004). The high number of plastids per plant cell (approximately 105 copies per plant cell) means that higher expression levels can be achieved than with a nuclear transformation. This is particularly desirable for a product-based transformation, where high protein yields are desirable (Dhinrga et al. 2004). The inheritance of the introduced transgene(s) will also be maternal and therefore offers a containment of the transgene due to the lack of gene flow through pollen (Daniell 2002), even though gene transfer from chloroplasts to nuclear genomes have been reported (Stegemann et al. 2003) but with extremely low frequencies. Plastid transformants have been produced in many species including $A$. thaliana (Sikdar et al. 1998). In addition, a Brassica chloroplast transformation by particle bombardment was reported in both $B$. oleracea (Hou et al. 2003) and $B$. napus (Liu et al. 2007) as well as in B. napus using a PEG-mediated approach (Nugent et al. 2006).

\section{Floral dipping/microinjection}

The ability to bypass the sometimes complex tissue culture phase associated with the above methods can potentially overcome some of the barriers to transformation success observed in Brassica. An in planta transformation of Arabidopsis is a common practice and involves immersing intact inflorescences in suspensions of A. tumefaciens (Kojima et al. 2006). The Agrobacterium targets the ovules for the transformation event (Ye et al. 1999). Therefore, species in which the ovary remains open for an extended developmental period may be good candidates for successful in planta transformation (Desfeux et al. 2000). Qing et al. (2000) reported a transformation by the infiltration of adult Brassica plants with Agrobacterium for B. rapa (Pakchoi). Although this efficiency was low, it did demonstrate the potential of this method for Brassica. Recently, Zhandong et al. (2007) reported a transformation rate of $2.35 \%$ infected with Turnip mosaic virus (TuMV) for Chinese cabbage (B. rapa) using the method reported by Liu et al. (1998). In B. napus, Wang et al. (2003) reported a success rate of $0.18 \%$ using a double infiltration approach. Verma et al. (2008) reported a simplified floral dip method for B. carinata and B. napus and Curtis and Nam (2001) reported a similar method for radish (Raphanus sativus L. longipinnatus Bailey). Reports of in planta transformation of Brassica are limited, and further studies on the parameters of the system will be needed before it can be exploited as a routine transformation method. The efficiencies reported to date for Brassica are similar to early reports in the model plant Arabidopsis. On the other hand, floral dipping may be more amenable to Arabidopsis owing to its size as well as its ease of handling, faster life cycle and smaller seed, which allows subsequent downstream screening for positive transgenics.

As an alternative to floral dipping, a microinjection of the bacteria directly into the flower bud (effectively flooding the bud cavity) before fertilization has been investigated. Yan et al. (2004) applied this technique successfully to $B$. rapa (Chinese cabbage). Efficiencies of up to $0.56 \%$ were obtained when the microinjection was carried out in the floral stage and when the concentration of Agrobacterium, sucrose and surfactant used was optimized. This efficiency was based on injecting approximately 50 flower buds with 
a size of 2-3 mm, from which they obtained 500-800 seeds yielding an average of three to four transgenics. Therefore, a microinjection also provides an alternative method for a Brassica transformation, particularly where the facilities for tissue culture-based techniques are unavailable.

\section{Selection of transgenics}

Selectable marker genes can be classed as either positiveor negative-based selection. Positive selectable marker genes are defined as those that promote the growth of transformed tissue, where the majority of work has centered on the use of modified sugars, such as mannose (Reed et al. 2001), disaccharide, cellobiouronic acid (CbA) (developed by the CAMBIA group, www.cambia.org), or glucose using the trehalose-6-phosphate synthase (TPS) system (Leyman et al. 2006). These types of selectable markers are likely to face fewer regulatory hurdles if the overall goal is commercial transgenic plants. Negative selection systems using toxic agents, such as antibiotics, herbicides or drugs, were the first to be developed and exploited. Kanamycin is the most commonly used negative selectable marker in most plant transformation work (Miki and McHugh 2004). The level of antibiotics used will depend on both the genotype and transformation method used; kanamycin has been applied in the range of $5 \mathrm{mg} / \mathrm{l}$ to $>200 \mathrm{mg} / \mathrm{l}$. Moloney et al. (1989) used $15 \mathrm{mg} / \mathrm{l}$ kanamycin to select transgenic shoots arising from cotyledonary explants of the B. napus cultivar Westar, whereas Cordoza and Stewart (2006) used $200 \mathrm{mg} / \mathrm{l}$ kanamycin on Westar hypocotyl explants. Hygromycin has also been used successfully in Brassica. Lee et al. (2004) reported hygromycin to be a more effective selection agent than kanamycin in the Brassica genotypes they tested; with very few escapes coming through the system. On the other hand, hygromycin may not be suitable for all genotypes because it is a much harsher selective agent than kanamycin. From a regulatory point of view, hygromycin, as a selectable marker, is unlikely to gain approval for field release. This is unlike kanamycin, which has achieved GRAS status (generally regarded as safe) (EU directive 2001/18). In such cases, studies to avoid marker genes or to eliminate them after use have been initiated and a growing number of methods are under development (Sundar et al. 2008; Rukavtsova et al. 2009). Recently, an Arabidopsis AtHOL1 gene with high S-adenosyl-L-methionine-dependent methyl-transferase activity towards the thiocyanate ion was used as a positive selection gene for an efficient selectable marker for screening the transformed seedlings of Arabidopsis (Midorikawa et al. 2009). Upadhyaya et al. (2010) also reviewed the development of marker-free transgenic plants. Basta or glufosinate (herbicide resistance) has also been used successfully in Brassica (de Block et al. 1989), even though it is less desirable for cotyledonary-based transformation methods because of mode of action of Basta in targeting photosynthetic materials. Basta is used frequently as a selectable marker for floral dipping or microinjection transformation methods, where large numbers of seeds can be soil sown and seedlings sprayed with Basta to select positive transgenics.

\section{Recovery of transgenic plants}

Plant regeneration is an indispensable tool for plant transformation. With the exception of the floral dip method, the transformation methods all rely on a robust regeneration system for transformation success. Regeneration protocols have been developed for most Brassica species and organogenesis is the pathway used most widely for regeneration. The regeneration of plants by organogenesis has been accomplished from a range of tissues, such as cotyledons (One et al. 1994; Yang et al. 2004), hypocotyls (Yang et al. 1991), peduncle segments (Eapen and George 1997), leaves (Radke et al. 1988), leaf sections (Alaska-Kennedy et al. 2005), anthers, microspores (Keller and Armstrong 1977; Litcher 1982), thin cell layers of epidermal and subepidermal cells (Klimaszewska and Keller 1985), roots (Xu et al. 1982), and protoplasts ( $\mathrm{Hu}$ et al. 1999). Nevertheless, it is the seedling explants (cotyledons and hypocotyls) that remain favorites for the transformation, and have been used for most Brassica species because of their ability to regenerate. The following discusses many of the factors that affect the successful regeneration of shoots in vitro.

Genotype and explant

The genotype-dependent nature of in vitro shoot regeneration, both within and among Brassica species, was first reported by Murata and Orton (1987), who suggested shoot regeneration to be a heritable trait. Sparrow et al. (2004) examined the genetic control of shoot regeneration from cotyledonary petioles using diallel crosses in $B$. napus and $B$. oleracea, respectively. A large variation was observed in the regeneration frequency of 51 genotypes of $B$. carinata (Gil-Humanes et al. 2011). In B. napus there was a huge variation in the 100 cultivars tested, ranging from $0 \%$ to $91 \%$ (Ono et al. 1994). Of the 123 genotypes of Chinese cabbage (B. rapa ssp. pekinensis) tested, a large variation 
in regeneration frequency was observed, ranging from $95 \%$ to $0 \%$ (Zhang et al. 1998). Therefore, genotype specificity is a limiting factor in Brassica tissue culture and regeneration, which severely limits the germplasm that can be manipulated or improved. The age and size of the explant is also critical for optimal results. For example, 3-day-old seedlings of B. rapa ssp. oleifera yielded better regeneration than those older than 4 days (Burnett et al. 1994). In B. napus, 4-day-old seedling explants proved optimal, yielding a $90 \%$ regeneration rate (Ono et al. 1994). In rapid-cycling B. rapa, 3-day-old explants from seedlings were best for regeneration (Teo et al. 1997). In all these cases, the regeneration capacity decreased when the age of the seedling was increased above 4 days. For hypocotyl sections, older explants ( $8 \sim 10$ days) have also been used for $B$. napus allowing a larger number of explants to be obtained per seedling (Cardoza and Stewart 2006; Maheshwari et al. 2011). On the other hand, Gasic and Korban (2006) reported that hypocotyls from 3 4-day-old seedlings gave optimal results in $B$. juncea. What appears critical in both these systems, however, is the length of the hypocotyl section. Small sections were optimal, i.e. 5-10 mm sections (where smaller explants performed better). Long hypocotyl sections had a tendency to curl and therefore loose contact with the culture media.

\section{Media constituents}

Regeneration success is affected by the choice of transformation protocol, hormones and the levels of other media additives used. Hypocotyl and leaf sections often require a callus phase prior to shoot regeneration (Yang et al. 2004; Gasic and Korban 2006). This is normally achieved using a high cytokinin (usually BAP) to low auxin (e.g. NAA) ratio. Gil- Humanes et al. (2011) obtained approximately $82 \%$ shoot regeneration from a hypocotyls culture using $5 \mathrm{mg} / \mathrm{l} \mathrm{BA}$ and $1 \mathrm{mg} / 1$ 2,4-D in B. napus. The regeneration efficiency was highest with BAP 3.0 $\mathrm{mg} / \mathrm{l} / \mathrm{NAA} 0.3 \mathrm{mg} / \mathrm{l}$ in $B$. juncea (Bano et al. 2010). The optimum regeneration was obtained using a combination of BAP $(3.0 \mathrm{mg} / \mathrm{l})$ and IAA $(0.2 \mathrm{mg} / \mathrm{l})$ in B. juncea (L) (Singh et al. 2009). Some transformation protocols also exploit a short callus induction phase prior to a transformation, a so-called preconditioning stage (Cardoza and Stewart 2006). In addition, a variety of media additives might increase the regeneration efficiencies in Brassica. Methylglyoxal-bis-(guanylhydrazone) (MGBG), an inhibitor of spermidine biosynthesis, was reported to increase the regeneration frequencies from $7 \%$ to $63 \%$ in Brassica and other genera (Sethi et al. 1990). Putrescine, a polyamine, however, was found to enhance shoot regeneration in Chinese radish when used with silver nitrate or aminoethoxyvinylglycine (Pua et al. 1996). On the other hand, putrescine was not effective when used alone, but was synergistic with ethylene inhibitors. Brassinolides, a relatively new class of compounds, have also been found to stimulate the production of adventitious shoots from cauliflower hypocotyl segments (Sasaki 2002). Infection was most effective (highest infection frequency) when Chinese cabbage explants were infected with Agrobacterium for $15 \mathrm{~min}$ and co-cultivated for 3 days in a co-cultivation medium at $\mathrm{pH}$ 5.2 supplemented with10 mg/l acetosyringone (Zhang et al. 2000).

Hyperhydricity and tissue necrosis is a serious problem for plant tissue culturists and many factors including the accumulation of ethylene and high humidity in culture vessels (de Block et al. 1989), excessively rich media (Ziv 1991), Agrobacterium overgrowth/sensitivity (Jin et al. 2000), and high doses of exogenous cytokinin and/or auxin (Kamal et al. 2007) are found to effect it. In $B$. napus (Cardoza and Stewart 2003), the relative humidity of the culture vessel and hyperhydricity decreased with increasing percentage of gelling agent (from $0.8 \%$ phytagar to $1.2 \%$ ) in the shoot elongation medium. Ethylene is another key factor in optimizing tissue culture conditions for some Brassica species (Cardoza and Stewart 2004). Silver nitrate has been used to reduce the hyperhydricity in a range of Brassica species, such as B. rapa (Yang et al. 2004) and B. napus (Tang et al. 2003). Excluding silver nitrate in the media drastically reduced the regeneration frequency of B. napus (Khan et al. 2002). In Chinese radish (Raphanus sativus var. longipinnatus), a combination of silver nitrate and aminoethoxyvinylglycine was found to enhance shoot regeneration significantly (Pua et al. 1996). Other ethylene inhibitors that can be used either in combination or as an alternative include silver thiosulphate (Eapen and George 1997) and aminoethoxyvinylglycine, which was used by Chi et al. (1990) for B. rapa and $B$. juncea, Pua and Chi (1993) for B. juncea, and Burnett et al. (1994) for B. rapa.

Rooting in vitro

Once shoot regeneration has been achieved from the desired genotype, another stumbling block can be the isolation of viable shoots. A shoot elongation step, where the cytokinin levels are lowered but not removed, can often help elongate the shoots (Cardoza and Stewart 2006; Bhalla and Singh 2008). Often hyperhydricity is overcome once the shoots have elongated, but occasionally, other 
supplements need to be explored. Rooting is often achieved by simply removing the cytokinin (Sparrow et al. 2006b). Nevertheless, in some cases it may also require the addition of an auxin (such as NAA or indole-3-butyric acid (IBA)) (Cardoza and Stewart 2006; Verma and Singh 2007; Bhalla and Singh 2008; Singh et al. 2009).

\section{Conclusions and future prospects}

Plant cellular and molecular biology techniques have tremendous potential for plant improvement. Among these techniques transformation can be of use in the development of plants with novel desirable traits with high accuracy. Many genetic improvements with the highest impact have come from genetic transformation. A range of transformation techniques have been used to introduce a wealth of agronomically useful traits into Brassicaceae such as insect/disease/bacterial/fungal/viral and herbicide resistance, those involved in flowering control, post-harvest attributes, altered stress tolerance, and altered health benefits including altering the anthocynanin/sulphur/vitamin or amino acid levels (reviewed by Christey and Braun 2007). This is expected to continue at an even higher rate in the years to come. The knowledge that has now been obtained in Arabidopsis and other plant species creates exciting opportunities for testing crop plants, such as Brassica. There have already been reports suggesting that transferring knowledge and technology from Arabidopsis to Brassica will be feasible in many cases (Østergaard et al. 2006; Lee et al. 2007). The extensive knowledge on how fruit development in Arabidopsis is regulated showed that it is possible to produce pod shatter-resistant Brassica fruits by overexpressing the MADS box gene fruitful from Arabidopsis in B. juncea (Østergaard et al. 2006). This manipulation resulted in a loss of highly specified valve margin tissue in fruits and consequently to pod shatter resistance, as was also observed in Arabidopsis (Ferrándiz et al. 2000). Pod shattering is just one example of an important trait that can be manipulated based on previous knowledge from Arabidopsis. Since oilseed rape is a relatively young crop compared to wheat, barley, rice, and maize, there is considerable room for improving other traits. These include the flowering time, branching, canopy architecture, fatty acid composition, overall seed oil production, and disease resistance. The transformation of Brassicaceae is likely to play a key role in obtaining the goals for crop improvement. Therefore it is important to keep optimizing and refining the current protocols as well as developing new approaches.

\section{Acknowledgements}

This work was supported by the Cabbage Genomics assisted breeding supporting center research program funded by Ministry for Food, Agriculture, Forestry and Fisheries of the Korean Government.

\section{References}

Alaska-Kennedy Y, Yoshida H, Takahata Y (2005) Efficient plant regeneration from leaves of rapeseed (Brassica napus L.): the influence of $\mathrm{AgNO}_{3}$ and genotype. Plant Cell Rep 24:649-654

Alonso JM, Stepanova AN, Leisse TJ (2003) Genomewide insertional mutagenesis of Arabidopsis thaliana. Science 301:653-657

An, G,Watsen BD, Chiang CC (1986) Transformation of tobacco, tomato, potato, and Arabidopsis thaliana using a binary $\mathrm{Ti}$ vector system. Plant Physiol 81:301-305

Babic V, Datla RS, Scoles GJ, Keller WA (1998) Development of an efficient Agrobacterium-mediated transformation system for Brassica carinata. Plant Cell Rep 17:183-188

Bano R, Khan MH, Khan RS, Rashid H, Swati ZA (2010) Development of an efficient regeneration protocol for three genotypes of Brassica juncea. Pak. J. Bot., 42(2):963-969

Barfield DG, Pua EC (1991) Gene transfer in plants of Brassica juncea using Agrobacterium tumefaciens mediated transformation. Plant Cell Rep 10:308-314

Bartlett JG, Alves SC, Smedley M, Snape JW, Harwood WA (2008) High throughput Agrobacterium-mediated barley transformation. Plant Methods 4:22

Bent A (2006) Arabidopsis thaliana floral dip transformation method. In: Wang K (ed) Agrobacterium Protocols, 2nd edn. Humana press, Totowa, NJ

Bevan M (1984) Binary Agrobacterium vectors for plant transformation. Nucleic Acids Res 12:8711-8721

Bhalla PL, Singh M(2008) Agrobacterium-mediated transformation of Brassica napus and Brassica oleracea. Nat Protoc 2:181-189

Bhuiyan MSU, Min SR, Jeong WJ, Sultana S, Choi KS, Lim YP, Song WY, Lee Y, Liu JR (2011) An improved method for Agrobacterium-mediated genetic transformation from cotyledon explants of Brassica juncea. Plant Biotechnology 28:17-23

Burnett L, Arnoldo M, Yarrow S, Huang B (1994) Enhancement of shoot regeneration from cotyledon explants of Brassica rapa ssp. oleifera through pretreatment with auxin and cytokinin and use of ethylene inhibitors. Plant Cell Tissue Organ Cult 37:253-256

Cao J, Shelton AM, Earle ED (2008) Sequential transformation to pyramid two $\mathrm{Bt}$ genes in vegetable Indian mustard (Brassica juncea L.) and its potential for control of diamondback moth larvae. Plant Cell Rep 27:479-487

Cao J, Tang JD, Strizhov N, Shelton AM, Earle ED (1999) Transgenic broccoli with high levels of Bacillus thuringiensis 
Cry1C protein control diamondback moth larvae resistant to CrylA or CrylC. Mol Breed 5:131-141

Cardoza V, Stewart N (2003) Increased Agrobacterium-mediated transformation and rooting efficiencies in canola (Brassica napus L.) from hypocotyl segment explants. Plant Cell Rep 21:599-604

Cardoza V, Stewart N (2004) Invited review: Brassica biotechnology: progress in cellular and molecular biology. In Vitro Cell Dev Biol Plant 40:542-551

Cardoza V, Stewart N (2006) Canola (Brassica napus L.). In: Wang K (ed) Agrobacterium protocols, 2nd edn. Methods in molecular biology 343, vol 1. Humana Press, Totowa, NJ

Chi GL, Barfield DG, Sim GE, Pua EC (1990) Effect of $\mathrm{AgNO}_{3}$ and aminovinylglycine on in vitro shoot and root organogenesis from seedling explants of recalcitrant Brassica genotypes. Plant Cell Rep 9:195-198

Cho H, Cao J, Ren J, Earle E (2001) Control of lepidopteran insect pests in transgenic Chinese cabbage (Brassica rapa ssp. Pekinensis) transformed with a synthetic bacillus thuringiensis cry1C gene. Plant Cell Rep 20:1-7

Christey MC (2001) Use of RI-mediated transformation for production of transgenic plants. In Vitro Cell Dev Biol Plant 37:687-700

Christey MC, Braun RH (2007) Vegetable Brassicas. In: Kole C, Hall TC (eds) A compendium of transgenic crop plants. Vegetable crops, vol 7. Wiley-Blackwell

Christey MC, Sinclair BK, Brassicas RH, Wyke L (1997) Regeneration of transgenic vegetable Brassicas (Brassica oleracea and B. campestris) via Ri-mediated transformation. Plant Cell Rep 16:587-593

Collier R, Fuchs B, Walter N, Lutke WK, Taylor CG (2005) Ex vitro composite plants: an inexpensive, rapid method for root biology. Plant J 43:449-457

Curtis IS, Nam HG (2001) Transgenic radish (Raphanus sativus L. longipinnatus Bailey) by floral-dip method - plant development and surfactant are important in optimizing transformation efficiency. Trans Res 10:363-371

Damm B, Scmidt R, Willmitz L (1989) Efficient transformation of Arabidopsis thaliana using direct gene transfer to protoplasts. Mol Gen Genet 217:6-12

Daniell H (2002) Molecular strategies for gene containment in transgenic crops. Nat Biotechnol 20:581-586

De Block M, Tenning P, de Brouwer D (1989) Transformation of Brassica napus and Brassica oleracea using Agrobacterium tumefaciens and the expression of the bar and neo genes in the transgenic plants. Plant Physiol 91(2):694-701

Desfeux C, Clough SJ, Bent AF (2000) Female reproductive tissues are the primary target of Agrobacterium-mediated transformation by the Arabidopsis floral-dip method. Plant Physiol 123:895-904

Dhinrga A, Portis AR, Daniell H (2004) Enhanced translation of a chloroplast expressed $\mathrm{RbcS}$ gene restores small subunit levels and photosynthesis in nuclear RbcS antisense plants. Proc Natl Acad Sci USA 101(6315):6320

Eapen S, George L (1997) Plant regeneration from peduncle segments of oil seed Brassica species: influence of silver nitrate and silver thiosulfate. Plant Cell Tissue Organ Cult 51:228-232

Ecker JR, Davis RW (1986) Inhibition of gene-expression in plant-cells by expression of antisense RNA. Proc Natl Acad Sci USA 83:5372-5376

Eimert K, Siegemund F (1992) Transformation of cauliflower (Brassica oleracea L.var. botrytis)-an experimental survey. Plant Mol Biol 19:485-490

Ferrándiz C, Liljegren SJ, Yanofky MF (2000) Negative regulation of the SHATTERPROOF genes by FRUITFULL during Arabidopsis fruit development. Science 289:436-438

Fobis-Loisy I, Chambrier P, Gaude T (2007) Genetic transformation of Arabidopsis lyrata: specific expression of the green fluorescent protein (GFP) in pistil tissues. Plant Cell Rep 26:745-753

Franco-Zorrilla JM, Valli A, Todesco M, Mateos I, Puga MI, Rubio-Somoza I, Leyva A, Weigel D, Garcia JA, Paz-Ares J (2007) Target mimicry provides a new mechanism for regulating microRNA activity. Nat Genet 39:1033-1037

Fukuoka H, Ogawa T, Matsuoka M, Ohkawa Y, Yano H (1998) Direct gene delivery into isolated microspores of rapeseed (Brassica napus L.) and the production of fertile transgenic plants. Plant Cell Rep 17:323-328

Gasic K, Korban SS (2006) Indian mustard [Brassica juncea (L.) Czern]. In: Wang K (ed) Agrobacterium Protocols, 2nd edn. Humana Press, Totowa, NJ

Gil-Humanes J, Martín A, Barro F (2011) Characterization of a Collection of Brassica carinata Genotypes for in vitro Culture Response and Mode of Shoot Regeneration. American Journal of Plant Sciences. 2:27-34. doi:10.4236/ajps.2011. 21003

Gupta V, Sita GL, Shaila MS, Jagannathan V (1993) Genetic transformation of Brassica nigra by Agrobacterium based vector and direct plasmid uptake. Plant Cell Rep 12:418-421

Halfhill M, Millwood RJ, Raymer PL, Stewart C Jr (2002) Bt-transgenic oilseed rape hybridization with its weedy relative, Brassica rapa. Environ Biosafety Res 1:19-28

Hellens R, Mullineaux P, Klee H (2000) Technical focus: a guide to Agrobacterium binary Ti vectors. Trends Plant Sci 5(10): 446-451

Hoekema A, Hirsch P, Hooykaas P, Schilperoort R (1983) A binary plant vector strategy based on separate vir and T region of the Agrobacterium tumefaciens Ti plasmid. Nature 303:179-180

Hood EE, Helmer GL, Fraley RT, Chilton MD (1986) The hypervirulence of Agrobacterium tumefaciens A281 is encoded in a region of pTiBo542 outside of T DNA. J Bacteriol 168:1291-1301

Hou B, Zhou Y, Wan L, Zhang Z, Shen G, Chen Z, Hu Z (2003) Chloroplast transformation in oilseed rape. Transgenic Res 12:111-114

$\mathrm{Hu}$ Q, Anderson SB, Hansen LN (1999) Plant regeneration capacity of mesophyll protoplasts from Brassica napus and related species. Plant Cell Tiss Organ Cult 59:189-196

James C (2007) Global status of commercialized biotech/GM 
crops: Brief No. 37. ISAAA, Ithaca, NY

Jin RG, Liu YB, Tabashnik BE, Borthakur D (2000) Development of transgenic cabbage (Brassica oleracea var. capitata) for insect resistance by Agrobacterium tumefaciens-mediated transformation. In Vitro Cell Dev Biol Plant 36:231-237

Jones JDG, Shlumukov L, Carland F, English J, Scofield SR, Bishop GJ, Harrison K (1992) Effective vectors for transformation, expression of heterologous genes, and assaying transposon excision in transgenic plants. Transgenic Res 1:285-297

Kamal GB, Lllich KG, Asadollah A (2007) Effects of genotype, explant type and nutrient medium components on canola (Brassica napus L.) shoot in vitro organogenesis. Afr $\mathrm{J}$ Biotechnol 6:861-867

KellerWA, Armstrong KC (1977) Embryogenesis and plant regeneration in Brassica napus anther cultures. Can J Bot 55:1383-1388

Khan M R, Hamid Rashid1 and Azra Quraishi (2002) High Frequency Shoot Regeneration from Hypocotyl of Canola (Brassica napus L.) cv. Dunkled. Plant Tissue Cult 12(2): 131-138

Klimaszewska K, Keller K (1985) High frequency plant regeneration from thin cell layer explants of Brassica napus. Plant Cell Tiss Organ Cult 4:183-197

Kojima M, Sparthana P, Teixeira da Silva JA, Nogawa M (2006) Development of in planta transformation methods using Agrobacterium tumefaciens. In: Teixeira da Silva JA (ed) Floriculture, ornamental and plant biotechnology: advances and topical issues, vol II, 1st edn. Global Science Books, Isleworth, UK

Koncz C, Schell J (1986) The promoter of TL-DNA gene 5 controls the tissue-specific expression of chimeric genes carried by a novel type of Agrobacterium binary vector. Mol Gen Genet 204:383-396

Kuvshinov V, Koivu K, Kanera A, Perhu E (1999) Agrobacterium tumefaciens mediated transformation of greenhouse-grown Brassica rapa ssp. oleifera. Plant Cell Rep 18:733-777

Lall S, Nettleton D, Decook R, Che P, Howell S (2004) Quantitative trait loci associated with adventitious shoot formation in tissue culture and the program of shoot development in Arabidopsis. Genetics 167:1883-1892

Lazo GR, Stein PA, Ludwig RA (1991) A DNA transformationcompetent Arabidopsis genomic library in Agrobacterium. Biotechnology 9:963-967

Lee JH, Park SH, Lee JS, Ahn JH (2007) A conserved role of SHORT VEGETATIVE PHASE (SVP) in controlling flowering time of Brassica plants. Biochim Biophys Acta 1769:455-461

Lee MK, Kim HS, Kim JS, Kim SH, Park YD (2004) Agrobacterium-mediated transformation system for largescale production of transgenic Chinese cabbage (Brassica rapa L. ssp. pekinensis) plants for insertional mutagenesis. J Plant Biol 47:300-306

Leyman B, Avonce N, Ramon M, Van Dijck P, Iturriaga G, Thevelein JM (2006) Trehalose-6-phosphate synthase as an intrinsic selection marker for plant transformation. J Biotechnol 121:309-317
Litcher R (1982) Induction of haploid plants from isolated pollen of Brassica napus. Plant Physiol (formally Z. Pflanzenphysiol) 105:427-434

Liu C, Lin C, Chen JJW, Tseng M (2007) Stable chloroplast transformation in cabbage (Brassica oleracea L. var. capitata L.) by particle bombardment. Plant Cell Rep 26:1733-1744

Liu F, Cao MQ, Yao L, Robaglia C, Tourneur C (1998) In Planta transformation of pakchoi (Brassica campestris L. ssp. chinensis) by infiltration of adult plants with Agrobacterium. Acta Hortic 467:187-192

Lloyd AM, Barnason AR, Rogers SG, Byrne MC, Fraley RT, Horsch RB (1986) Transformation of Arabidopsis thaliana with Agrobacterium tumefaciens. Science 234:464-466

Maheshwari P, Selvaraj G, Kovalchuk I (2011) Optimization of Brassica napus (canola) explant regeneration for genetic transformation. New Biotechnology 29:(1) 145-155

Maliga P (2004) Plastid transformation in higher plants. Annu Rev Plant Biol 55:289-313

Mehra S, Pareek A, Bandyopadhyay P, Sharma P, Burma PK, Pental D (2000) Development of transgenics in Indian oilseed mustard (Brassica juncea) resistant to herbicide phosphinothricin. Curr Sci 78:1358-1364

Midorikawa K, Nagatoshi Y, Nakamura T (2009) A selection system for transgenic Arabidopsis thaliana using potassium thiocyanate as the selective agent and AtHOL1 as the selective marker. Plant Biotechnol 26:341-344

Mietkiewska E, Hoffman TL, Brost JM (2008) Hairpin-RNA mediated silencing of endogenous FAD2 gene combined with heterologous expression of Crambe abyssinica FAE gene causes an increase in the level of erucic acid in transgenic Brassica carinata seeds. Mol Breed 22:619-627

Miki B, McHugh S (2004) Selectable marker genes in transgenic plants: applications, alternatives and biosafety. J Biotechnol 107:193-232

Moloney MM, Walker JM, Sharma KK (1989) High-efficiency transformation of Brassica napus using Agrobacterium vectors. Plant Cell Rep 8:238-242

Mukhopadhyay A, Topfer R, Pradhan AK, Sodhi YS, Steinbiss HH, Schell J, Pental D (1991) Efficient regeneration of Brassica oleracea hypocotyl protoplasts and high frequency genetic transformation by direct DNA uptake. Plant Cell Rep 10:375-379

Murata M, Orton TJ (1987) Callus initiation and regeneration capacities in Brassica species. Plant Cell Tissue Organ Cult 11:111-123

Narasimhulu SB, Kirti PB, Mohapatra T, Prakash S, Chopra VL (1992) Shoot regeneration in stem explants and its amenability to Agrobacterium tumefaciens mediated gene transfer in Brassica carinata. Plant Cell Rep 11:359-362

Nugent GD, Coyne S, Ngyuen TT, Kavanagh TA, Dix PJ (2006) Nuclear and plastid transformation of Brassica oleracea var. botrytis (cauliflower) using PEG-mediated uptake of DNA into protoplasts. Plant Sci 170:135-142

Ono Y, Takahata Y, Kaizuma N (1994) Effect of genotype on shoot regeneration from cotyledonary explants of rapeseed (Brassica 
napus L.). Plant Cell Rep 14:13-17

Østergaard L, Kempin SA, Bies D, Klee HJ, Yanofsky MF (2006) Pod shatter resistant fruit produced by ectopic expression of the FRUITFULL gene in Brassica juncea. Plant Biotechnol 4:45-51

Poulsen GB (1996) Genetic transformation of Brassica. Plant Breed. 115:209-225

Pua EC, Chi GL (1993) De novo shoot morphogenesis and plant growth of mustard (Brassica juncea) in vitro in relation to ethylene. Physiol Plant 88:467-474

Pua EC, Sim GE, Chi GL, Kong LF (1996) Synergistic effect of ethylene inhibitors and putrescine on shoot regeneration from hypocotyls explants of Chinese radish (Raphanus sativus L. var. longipinnatus Bailey) in vitro. Plant Cell Rep 15:685-690

Puddephat IJ, Robinson HT, Fenning TM, Barbara DJ, Morton A, Pink DAC (2001) Recovery of phenotypically normal transgenic plants of Brassica oleracea upon Agrobacterium rhizogenesmediated co-transformation and selection of transformed hairy roots by GUS assay. Mol Breed 7:229-242

Puddephat IJ, Thompson N, Robinson HT Sandhu P, Henderson J (1999) Biolistic transformation of broccoli (Brassica oleracea var. Italica) for transient expression of the $\beta$-glucuronidase gene. J Hortic Sci Biotechnol 74:714-720

Purty RS, Gautam K, Singla-Pareek SL (2008) Towards salinity tolerance in Brassica: an overview. Physiol Mol Biol Plants 14:39-49

Qing CM, Fan L, Lei Y, Bouchez D, Tourneur C, Yan L, Robaglia C (2000) Transformation of Pakchoi (Brassica rapa L. ssp. chinensis) by Agrobacterium infiltration. Mol Breed 6:67-72

Radchuck V, Ryschka U, Schumann G, Klocke E (2002) Genetic transformation of cauliflower (Brassica oleracea var. botrytis) by direct DNA uptake into mesophyll protoplasts. Physiol Plant 114:429-438

Radke SE, Andrews BM, Moloney MM, Crouch ML, Krid JC, Knauf VC (1988) Transformation of Brassica napus L. using Agrobacterium tumefaciens: developmentally regulated expression of a reintroduced napin gene. Theor Appl Genet 75:685-694

Reed J, Privalle L, Luann Powell M, Meghji M, Dawson J, Dunder E, Sutthe J, Wenck A, Launis K, Kramer C, Chang YF, Hansen G, Wright M (2001) Phosphomannose isomerase: an efficient selectable marker for plant transformation. In Vitro Cell Dev Biol Plant 37:127-132

Rukavtsova EB, Zakharchenko NS, Pigoleva SV, Yukhmanova AA, Chebotareva EN, Bur'yanov YaI (2009) Obtaining marker-free transgenic plants. Biochem Bioph 426:143-146

Sasaki H (2002) Brassinolide promotes adventitious shoot regeneration from cauliflower hypocotyl segments. Plant Cell Tiss Organ Cult 71:111-116

Schwab R, Ossowski S, Riester M, Warthmann N, Weigel D (2006) Highly specific gene silencing by artificial micoRNAs in Arabidopsis. Plant Cell 18:1121-1133

Sciaky D, Montoya AL, Chilton MD (1978) Fingerprints of Agrobacterium Ti plasmids. Plasmid 1:238-253

Sethi U, Basu A, Mukherjee SG (1990) Role of inhibitors in the induction of differentiation in callus cultures of Brassica,
Datura and Nicotiana. Plant Cell Rep 8:598-600

Sikdar S, Serino G, Chaudhuri S, Maliga P (1998) Plastid transformation in Arabidopsis thaliana. Plant Cell Rep 18:20-24

Singh VV, Verma V, Pareek AK, Mathur M, Yadav R, Goyal P, Thakur AK, Singh YP, Koundal KR, Bansal KC, Mishra AK, Kumar A, Kumar S (2009) Optimization and development of regeneration and transformation protocol in Indian mustard using lectin gene from chickpea [Cicer arietinum (L.)] .J of Plant Breeding and Crop Sci1(9):306-310

Somerville C, Koorneef M (2002) A fortunate choice: the history of Arabidopsis as a model plant. Nat Rev Genet 3:883-889

Sparrow PAC, Dale PJ, Irwin JA (2006b) Brassica oleracea. In: Wang K (ed) Agrobacterium Protocols, 2nd edn. Methods in molecular biology 343, vol 1. Humana Press, Totowa, NJ

Sparrow PAC, Snape JW, Dale PJ, Irwin JA (2006a) The rapid identification of B. napus genotypes, for high-throughput transformation, using phenotypic tissue culture markers. Acta Hortic 706:239-247

Sparrow PAC, Townsend T, Morgan CL, Arthur AE, Dale PJ, Irwin JA (2004) Genetic analysis of in vitro shoot regeneration from cotyledonary petioles of Brassica oleracea. Theor Appl Genet 108:1249-1255

Stegemann S, Hartmann S, Ruf S, Bock R (2003) High-frequency gene transfer from the chloroplast genome to the nucleus. Proc Natl Acad Sci USA 100:8828-8833

Sundar IK, Sakhtivel N (2008) Advances in selectable marker genes for plant transformation. J Plant Physiol 165:1698 $-1716$

Takasaki T, Hatakeyama K, Hinata K (2004) Effect of silver nitrate on shoot regeneration and Agrobacterium-mediated transformation of Turnip (Brassica rapa L. var. rapifera). Plant Biotechnol 21 (3):225-228

Tang GX, Zhou WJ, Li HZ, Mao BZ, He ZH, Yoneyama K(2003) Medium, explant and genotype factors influencing shoot regeneration in oilseed Brassica spp. J Agron Crop Sci 189:351-358

Teo W, Lakshmanan P, Kumar P, Goh CJ, Swarup S (1997) Direct shoot formation and plant regeneration from cotyledon explants of rapid-cycling Brassica rapa. In Vitro Cell Dev Biol Plant 33:288-292

Upadhyaya CP, Nookaraju A, Gururani MA, Upadhyaya DC, Kim DH, Chun SC, Park SW (2010) An update on the progress towards the development of marker-free transgenic plants. Botanical Studies 51:277-292

Veena V, Taylor CG (2007) Agrobacterium rhizogenes: recent developments and promising applications. In Vitro Cell Dev Biol 43:383-403

Verma SS, Chiinnusarny V, Bansal KC (2008) A simplified floral dip method for transformation of Brassica napus and $B$. carinata. J Plant Biochem Biotechnol 17:197-200

Wahlroos T, Susi P, Tylkina L, Malyshenko S, Zvereva S, Korpela T (2003) Agrobacterium-mediated transformation and stable expression of the green fluorescent protein in Brassica rapa. Plant Physiol and Biochem 41 (9):773-778

Wang WC, Menon G, Hansen G (2003) Development of a novel 
Agrobacterium mediated transformation method to recover transgenic Brassica napus plants. Plant Cell Rep 22:274-281

Warwick SI, Gugel R, McDonald T et al (2006) Genetic variation and agronomic potential of Ethiopian mustard (Brassica carinata) in western Canada. Genet Resour Crop Evol 53: 297-312

Warwick SI, Légère A, Simard MJ et al (2008) Do escaped transgenes persist in nature? The case of an herbicide resistance transgene in a weedy Brassica rapa population. Mol Ecol 17:1387-1395

Warwick SI, Simard MJ, Légère A et al (2003) Hybridization between transgenic Brassica napus L. and its wild relatives: Brassica rapa L, Raphanus raphanistrum L, Sinapis arvensis L., and Erucastrum gallicum (Willd.) O. E. Schulz. Theor Appl Genet 107:528-539

Xu ZH, Davey MR, Cocking EC (1982) Plant regeneration from root protoplasts of Brassica. Plant Sci Lett 24:117-121

Yan JY, He YK, Cao JS (2004) Factors affecting transformation efficiency by micro-injecting Agrobacterium into flower bud of Chinese cabbage. Agric Sci China 3:44-51

Yang MZ, Jia SR, Pua EC (1991) High frequency of plant regeneration from hypocotyl explants of Brassica carinata A. Br. Plant Cell Tiss Organ Cult 24:79-82
Yang ZH, Jin H, Plaha P, Woong BT, Jiang GB, Woo JG, Yun HD, Lim YP, Lee HY (2004) An improved regeneration protocol using cotyledonary explants from inbred lines of Chinese cabbage (Brassica rapa ssp. pekinensis). J Plant Biotechnol 6:235-239

Ye GN, Stone D, Pang SZ, Creely W, Gonzalez K, Hinchee M (1999) Arabidopsis ovule is the target for Agrobacterium in planta vacuum infiltration transformation. Plant J 19:249-257

Zhandong Y, Shuangyi Z, Qiwei H (2007) High level resistance to Turnip mosaic virus in Chinese cabbage (Brassica campestris ssp. pekinensis (Lour) Olsson) transformed with the antisense NIb gene using marker-free Agrobacterium tumefaciens infiltration. Plant Sci 172:920-929

Zhang FL, Takahata Y, Watanabe M, Xu JB (2000) Agrobacterium -mediated transformation of cotyledonary explants of Chinese cabbage (Brassica campestris L. ssp. pekinensis). Plant Cell Rep 19:569-575

Zhang FL, Takahata Y, Xu JB (1998) Medium and genotype factors influencing shoot regeneration from cotyledonary explants of Chinese cabbage (Brassica campestris L. ssp. pekinensis). Plant Cell Rep 17:780-786

Ziv M (1991) Quality of micropropagated plants-vitrification. In Vitro Cell Dev Biol Plant 27:64-69 